\title{
Microfabrication and Characterization of Teflon AF-Coated Liquid Core Waveguide Channels in Silicon
}

\author{
Arindom Datta, In-Yong Eom, Achintya Dhar, Petr Kuban, Rosalynn Manor, Iftikhar Ahmad, Shubhra Gangopadhyay, \\ Tim Dallas, Mark Holtz, Henryk Temkin, Fellow, IEEE, and Purnendu K. Dasgupta
}

\begin{abstract}
The fabrication and testing of Teflon AF-coated channels on silicon and bonding of the same to a similarly coated glass wafer are described. With water or aqueous solutions in such channels, the channels exhibit much better light conduction ability than similar uncoated channels. Although the loss is greater than extruded Teflon AF tubes, light throughput is far superior to channels described in the literature consisting of [110] planes in silicon with $45^{\circ}$ sidewalls. Absorbance noise levels under actual flow conditions using an LED source, an inexpensive photodiode and a simple operational amplifier circuitry was $1 \times 10^{-4}$ absorbance units over a 10-mm path length (channel $0.17-\mathrm{mm}$ deep $\times 0.49-\mathrm{mm}$ wide), comparable to many commercially available macroscale flow-through absorbance detectors. Adherence to Beer's law was tested over a 50-fold concentration range of an injected dye, with the linear $r^{2}$ relating the concentration to the observed absorbance being 0.9993 . Fluorescence detection was tested with fluorescein as the test solute, a high brightness blue LED as the excitation source and an inexpensive miniature PMT. The concentration detection limit was $3 \times 10^{-9} \mathrm{M}$ and the corresponding mass detection limit was estimated to be $5 \times 10^{-16} \mathrm{~mol}$.
\end{abstract}

\section{INTRODUCTION}

$\mathbf{S}$ ENSORS that rely on measurements of the liquid phase are important in chemical and biological monitoring. The most widely applied class of analytical techniques in the solution phase involves optical absorbance and fluorescence measurements. Since the range of wavelengths accessible by solid-state sources is continuously expanding, particularly into the ultraviolet, [1] and the fact that such sources (as well as solid state detectors) can be readily integrated with microfluidic devices, the optical measurements of liquid phase specimens will continue to show great promise for developing miniaturized sensors. However, optical measurements, especially absorbance, must overcome the sensitivity limitations associated with the short optical path lengths. To achieve long path lengths for chip-scale systems, so-called Z-path cells can be fabricated. However, light loss is especially severe in small cross section channels due to

Manuscript received October 28, 2002; revised April 14, 2003. This work was supported in part by the National Science Foundation under Grants CTS088198, ECS-0070240. The associate editor coordinating the review of this paper and approving it for publication was Dr. Michiel Vellekoop.

A. Datta, I.-Y Eom, A. Dhar, P. Kuban, R. Manor, I. Ahmad, T. Dallas, M. Holtz, H. Temkin, and P. K. Dasgupta are with the Nanotech Center, Texas Tech University (TTU), Lubbock, TX 79409 USA (e-mail: arindom.datta@ttu.edu; adhar@phy.iitkgp.ernet.in; petr.kuban@ttu.edu; rosalynnm@hotmail.com; Tim.dallas@coe.ttu.edu; htemkin@coe.ttu.edu; sandy.dasgupta@ttu.edu).

S. Gangopadhyay is with the University of Missouri, Columbia, MO 65201 USA.

Digital Object Identifier 10.1109/JSEN.2003.820343 absorption of light by the channel walls and their less than ideal reflectivity. Verpoorte et al. [2] etched silicon to produce microchannels with smooth [111] planar surfaces to improve wall reflectivity. More recently, Tiggelaar et al. [3] etched channels in silicon having surfaces $\left(45^{\circ}\right.$ sidewalls) and coated them with 40-nm thick Pt layers. They obtained photocurrents of $20 \mathrm{nA}$ for path lengths of 5-7 $\mathrm{mm}$ and cross-sectional areas of $0.14 \mathrm{~mm}^{2}$.

A different solution to the same problem of light loss to the wall has also been recently available. This is to make the optical measurement cell behave as an optical fiber, i.e., such that there is total internal reflection at the walls and the attenuation of light due to passage through the cell is primarily due to absorption by the analyte. Such a situation is achieved if the light-carrying liquid core is bounded by optically transparent walls that are made of a material with a refractive index (RI) less than that of the liquid core. Recently, a series of amorphous copolymersn [4]-[6] of polytetrafluoroethylene (PTFE) with 2,2-bis-(trifluoromethyl)-4,5-difluoro-1,3-dioxole has become commercially available. These polymers, generically called Teflon AF, are optically transparent and have a RI of 1.29-1.31, slightly lower than that of water (1.33). Either Teflon AF tubes, or Teflon AF-coated glass/fused silica capillaries, behave as liquid core wave guides (LCW) when filled with water or aqueous solutions when the liquid RI exceeds that of the polymer. The fact that Teflon AF LCW-based systems permit uniquely powerful fluorescence [7]-[12], chemiluminescence [13], [14], Raman [15]-[20] and absorption detection [24]-[33] capabilities is beginning to be widely exploited albeit not yet on the chip scale. Unique applications of LCWs based on plastic or glass capillaries coated with Teflon AF or tubes made of Teflon [34], [35] have also been described.

LCWs fabricated at the chip-scale have numerous potential applications ranging from high-throughput drug screening to clinical diagnostics and gene analysis. [36] We report here on the fabrication and testing of chip-scale Teflon AF-coated LCWs in microchannels etched in silicon substrates.

\section{EXPERIMENTAL DETAILS}

\section{A. Reagents}

Chemicals used $(\mathrm{KOH}$, acetone, ethanol, $\mathrm{HF})$ were electronic grade from Fisher Scientific (Fairlawn, NJ) except as stated. Perfluorooctyltrimethoxysilane $(0.4 \%$ solution in a high boiling fluorocarbon solvent, FluoroSy FSM 660) was obtained from Cytonix, Beltsville, MD. Teflon AF, 2400, 
1600, 1601S were obtained from Dupont (Wilmington, DE). Perfluoro(n-butyltetrahydrofuran) (FC-75) was obtained from 3M Corp (Minneapolis, MN).

\section{B. Etching Channels in Silicon}

The 2-in silicon (thickness $\sim 660-690 \mu \mathrm{m}$ ) wafers (Silicon Inc., Boise, ID) and 2-in Pyrex glass (RI 1.473) wafers (Precision Glass \& Optics, Santa Ana, CA) were used as substrates. The channels are etched only on the silicon, the glass serves as a cover plate. The silicon wafers were wet-oxidized for $\sim 5 \mathrm{~h}$, forming a $\sim 0.9-1.0 \mu \mathrm{m}$ oxide layer on wafer front and back. The oxide layer serves as a hard mask during the subsequent wet etching of $\mathrm{Si}$. The front-surface resist was patterned with both straight and curved channels (radius of curvature $r_{c}$ of 6.1 and $1.9 \mathrm{~cm}$, respectively) with a fixed channel width (at the top, the sidewalls are $\langle 111\rangle$ planes angled at $5.47^{\circ}$ ) of $500 \mu \mathrm{m}$. The backside of the wafer was also coated with photoresist to protect the oxide layer. A positive photoresist (S 1813, Shipley, Marlborough, MA) was used in this work. This prevented undesirable etching from the wafer backside during wet etching. After the photoresist was patterned and developed using standard photolithography processing, the exposed oxide was etched by dipping the wafer in a buffered oxide etch solution, [37] diluted 1:1 with deionized water. Exposed silicon was etched at $80^{\circ} \mathrm{C}$ with $25 \% \mathrm{KOH}$ (water bath) to form channels in silicon. Etching for $\sim 5.5 \mathrm{~h}$ under these conditions produced a channel depth of $\sim 180 \mu \mathrm{m}$. At this point, the oxide hard mask was removed from both the front and back of the Si wafer with $20 \%$ HF. Finally, the wafer was thoroughly cleaned with a standard acetone, alcohol, and DI water rinse.

\section{Adhesion Promoter Coating}

Teflon AF perfluorodioxole copolymers are nonpolar, contain no reactive chemical functionality, and are highly resistant to chemical attack. Thus, adhesion to substrates depends primarily on physical rather than chemical interactions [6]. In particular, Teflon AF exhibits practically no adhesion to untreated glass or $\mathrm{Si}$ surfaces. Two approaches were investigated to improve the adhesion of Teflon AF to Si and glass. We have used thin fluorocarbon films [38], [39] formed by plasma-enhanced-chemical vapor deposition (PECVD) using inductively-coupled high density plasma (HDP) methods [40]-[42]. Chemically active fluorine bonds in the plasma-generated fluorocarbon films promote the improved adhesion of Teflon AF to glass or silicon surfaces.

A simpler method relies on perfluorooctyltrimethoxysilane (0.4\% solution) spin-coated onto silicon or glass. [43] The coated wafers were immediately baked at $90{ }^{\circ} \mathrm{C}$ for $10 \mathrm{~min}$ in an oven. Teflon AF was then spin-coated and exhibited good adhesion.

\section{Coating of Teflon AF}

Three types of Teflon AF, namely 2400, 1600, 1601S (Dupont), were used for the fabrication of the LCWs. Relevant properties of these materials are listed in Table I. Dress et al. calculated that a $\sim 5 \mu$ thick film is necessary to confine the light to the liquid core [44]. Because of the low solids content
TABLE I

RELEVANT Physical PROPERTIES OF TEFlon AF COATINGS INVESTIGATED

\begin{tabular}{c|c|c|c}
\hline $\begin{array}{c}\text { Teflon AF type } \\
\text { (Solution) }\end{array}$ & $\mathbf{2 4 0 0}$ & $\mathbf{1 6 0 0}$ & $\mathbf{1 6 0 1 S}$ \\
\hline Viscosity $(\mathrm{Pa}-\mathrm{Sec})$ & 540 & 2657 & 5500 \\
\hline $\begin{array}{c}\text { Glass transition } \\
\text { Temperature } \mathrm{T}_{\mathrm{g}}\left({ }^{\circ} \mathrm{C}\right)\end{array}$ & $240 \pm 10$ & $160 \pm 5$ & 160 \\
\hline Refractive Index & 1.29 & 1.31 & 1.31 \\
\hline Concentration & $2 \mathrm{wt} \%$ solid & $6 \mathrm{wt} \%$ solid & $18 \mathrm{wt} \%$ solid \\
\hline
\end{tabular}

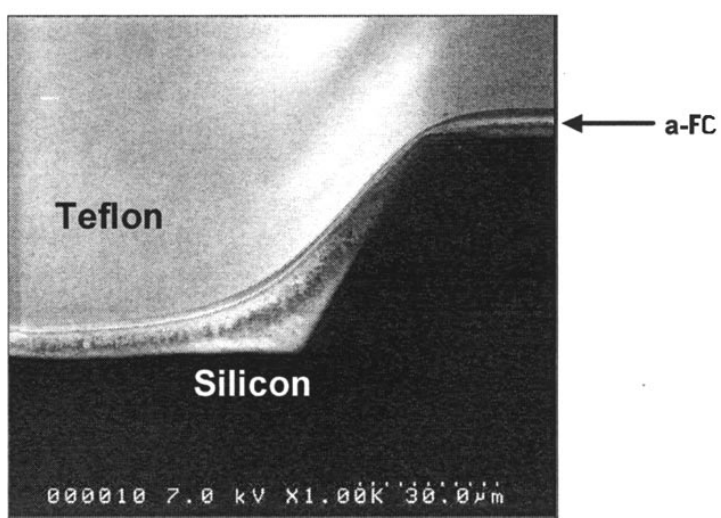

Fig. 1. Scanning electron micrograph of the Teflon AF-coated channel on a silicon wafer, shown in cross section. The adhesion promoting fluorocarbon layer is not visible at this scale.

and low viscosity of Teflon AF 2400, multiple coatings were needed to obtain a $1 \mu$ thick film. For Teflon AF 1600, a single coating produced a film thickness of $\sim 1.2 \mu \mathrm{m}$. Multiple coatings were needed with either Teflon AF 2400 or 1600 to obtain films with the necessary $>3 \mu \mathrm{m}$ thickness. The wafer was baked at $112{ }^{\circ} \mathrm{C}$ for $5 \mathrm{~min}$ after each spin coating, for partial removal of the solvent. This procedure produced films that were not uniform in thickness. In contrast, the high viscosity and high polymer concentration of Teflon AF $1601 \mathrm{~S}$ resulted in $15-20 \mu$ thick and uniform films with a single coating. The RI of these films, measured using a prism coupler operated at $632.8 \mathrm{~nm}$, was 1.30 . In order to reduce the thickness of the coated films, the solution was diluted using FC-75. The spin speed and Teflon AF 1601 to FC-75 ratio were varied to obtain films with thickness in the $1-20 \mu \mathrm{m}$ range. For the results presented here, we used a 2:1 Teflon AF 1601S:FC-75 ratio. At a spin speed of $4500 \mathrm{rpm}$, a single coating produced a film thickness of $4.4 \mu \mathrm{m}$. All the wafers were subjected to a baking cycle immediately after the coating step to remove the solvent as follows. a) Leave the coated substrate for 15-20 min at ambient temperature; b) bake at $112{ }^{\circ} \mathrm{C}$ for $15 \mathrm{~min}$; c) bake at $165{ }^{\circ} \mathrm{C}$ for $15 \mathrm{~min}$; d) bake at $330{ }^{\circ} \mathrm{C}$ for $30 \mathrm{~min}$. The baking procedure is essential for the complete removal of the solvent. Interestingly, the RI of the films remained unchanged even though the films were processed at temperatures above the glass transition temperature $\left(T_{g}=160{ }^{\circ} \mathrm{C}\right)$ of the films. The baking of Teflon AF above its $T_{g}$ softens the polymer and produces a smooth surface. A scanning electron micrograph of the cross section of the Si-channel coated with Teflon AF is shown in Fig. 1. A coating that conforms to the channels is evident. 
Process in $\mathrm{Si}$

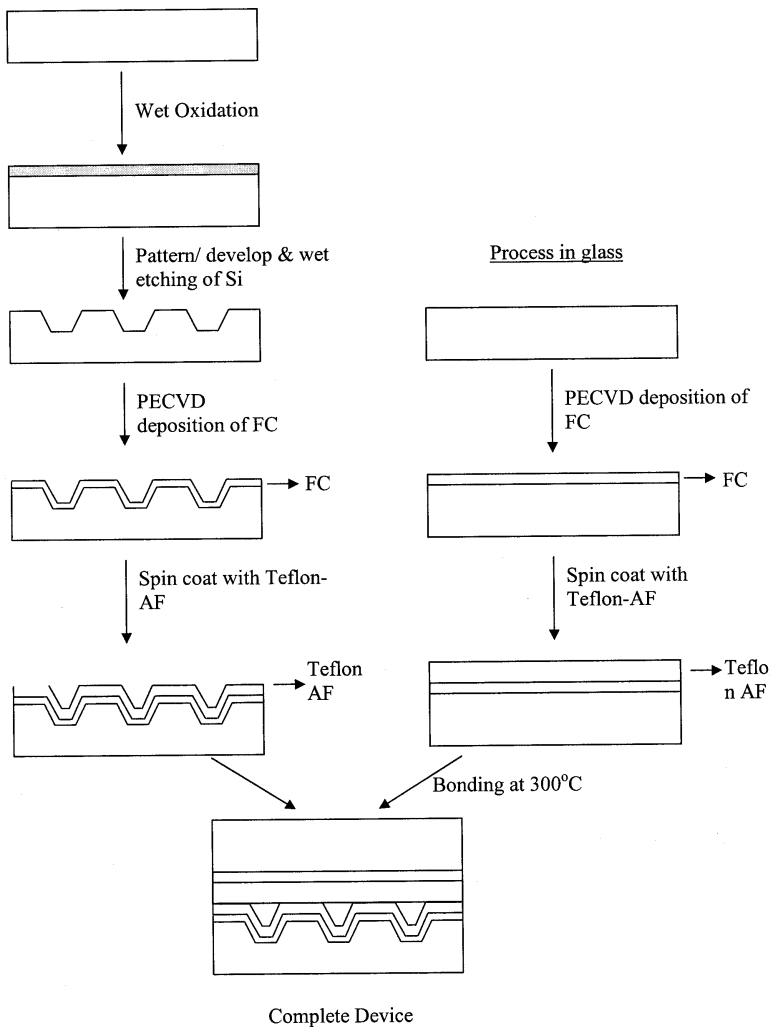

Fig. 2. Process flow schematic. Fabrication of a bonded liquid core wave guide (LCW) device fabricated on Si.

\section{E. Cover Bonding for Sealed LCW and Control Devices}

The Si wafer containing $180-\mu \mathrm{m}$ deep and $500-\mu \mathrm{m}$ wide channels and a Pyrex glass wafer, without channels, similarly coated with Teflon AF, as described in the previous section, were used to fabricate a sealed channel. Access holes to the channels had been made on the glass wafer with a $0.75-\mathrm{mm}$ diamond-tipped drill bit, using a programmable drill press, before coating the wafer with Teflon. No modification of the coating procedure from that used for the silicon wafer was found necessary for coating the drilled glass wafer. The Teflon AF-coated Si and glass wafers were aligned face-to-face and clamped together. The whole assembly was put into a furnace at $300{ }^{\circ} \mathrm{C}$ for $30 \mathrm{~min}$ and cooled to room temperature before removing the wafers from the clamping fixture. The sealed channels were leak-checked with water. The complete process flow diagram is depicted in Fig. 2.

A control device was made using uncoated (no Teflon AF) Si channels capped with a glass wafer. The control wafers were bonded to each after coating with $0.4-\mu \mathrm{m}$ thick poly-methylsilsesquioxane spin-on-glass (SOG) (Filmtronics Inc., PA), with an R.I. very close to that of glass. The SOG was spin-coated at $3500 \mathrm{rpm}$ for $30 \mathrm{~s}$. This SOG was chosen because it flows at relatively low temperature $\left(150{ }^{\circ} \mathrm{C}-210{ }^{\circ} \mathrm{C}\right)$. Bonding was carried out for $3 \mathrm{~h}$ at $300{ }^{\circ} \mathrm{C}$.

\section{F. Light Transmission Measurement}

A high brightness 660-nm light emitting diode (H-2000L, $5 \mathrm{~mm}$, rated to have a luminous output of $2000 \mathrm{mcd}$, when driven at $20 \mathrm{~mA}$, input power $36 \mathrm{~mW}$; Stanley Electric, Tokyo, Japan) was modified by removing most of the plastic encapsulant. A $0.5-\mathrm{mm}$ diameter hole was drilled under a microscope from the top of the LED to near the emitter surface, with the LED powered and where the highest emitted light intensity was observed, taking care to not damage the emitter chip or the bonding wire. A short $(5 \mathrm{~cm})$ bundle of $1370-\mu \mathrm{m}$ diameter glass optical fibers was put together, inserted into a Teflon $(0.25 \mathrm{~mm}$ i.d.; $0.5 \mathrm{~mm}$ o.d.) tube as a sleeve and held in place with silicone rubber adhesive.The fibers and the sleeve tubing were affixed into the hole with optical-grade, UV-cure adhesive (Type 81, Norland Products, Cranbury, NJ). The LED assembly was then covered with opaque epoxy (2-part epoxy, 1-part activated carbon) to eliminate ambient light. The free end of the fiber bundle was inserted into the channel under test and sealed in place with silicone rubber. This adhesive is removable and permits reuse of the fiber bundle. A similar fiber bundle was used at the other end of the channel, with the distal end epoxied to a small $(4 \times 5 \mathrm{~mm})$ photodiode (BPW34, Siemens), similarly sealed with black epoxy. The fiber bundle is fragile and movement of the fibers during measurement can cause noise/changes in signal. A small piece of acrylic sheet was used as a support and the fiber bundle was affixed thereon. The photocurrent was measured with a picoammeter (Keithley Instruments, model 480).

The channel under test in the control wafer was filled with deionized water ensuring that there were no air bubbles and the photocurrent measured with the LED driven at $20 \mathrm{~mA}$. The fiber bundle was then moved over to the corresponding channel in the LCW coated wafer. The transmittance was repeatedly measured in the corresponding channels in the respective wafers.

We also conducted direct transmission loss measurement as a function of channel length. Direct transmission loss measurement, as a function of length through the channels, is difficult because repeated movement of fibers can scratch channel surfaces and impair performance. The tube/channels were filled with a dilute solution of fluorescein and illuminated transversely at a measured distance from the exit using a near UV (385 nm) LED (UV-LED E1L5M, Roithner Lasertechnik) driven at $2.5 \mathrm{~mA}$ and focused to a spot approximately $100 \mu \mathrm{m}$ in diameter. Light emerging from one end of the tube/channels was imaged on a miniature CCD spectrometer (USB 2000, Ocean Optics Inc., Dunedin, FL). The fluorescence emission intensity at $540 \mathrm{~nm}$ is measured varying the distance of the LED illumination point from the tube/channel (observation) end. Measurements made on both the Teflon AF-coated and uncoated control micro-channels were compared with those made on a commercial Teflon AF tube with i.d. of $0.25 \mathrm{~mm}$.

\section{G. Measurements in a Flow Injection Analysis (FIA) Manifold}

The schematic of the FIA manifold is shown in Fig. 3. The FIA experiment used the curved LCW channel with a radius of curvature of $6.1 \mathrm{~cm}$, rather than a straight channel, to reject false signals arising from line of sight transmission. The fiber-to-fiber distance, including the channel curvature, was $10.4 \mathrm{~mm}$. An alkaline solution of bromthymol blue (BTB, molar absorptivity at $660 \mathrm{~nm} 11000 \mathrm{M}^{-1} \mathrm{~cm}^{-1}, 660 \mathrm{~nm}$ is not the wavelength of maximum absorption for BTB), $70 \mu \mathrm{M}$ in concentration, was used as the test analyte. A solution of 


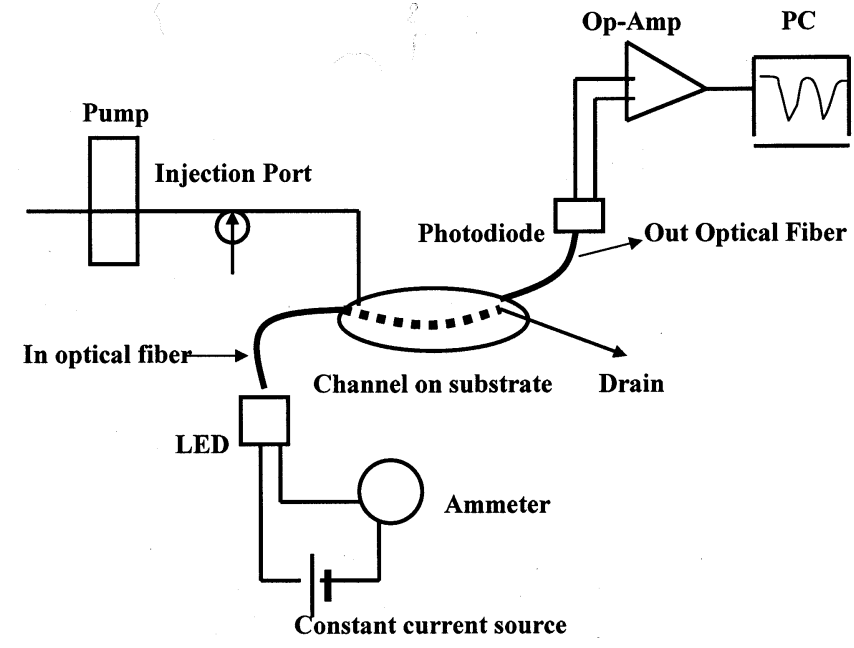

Fig. 3. Arrangement for flow injection and absorbance detection, schematically shown.

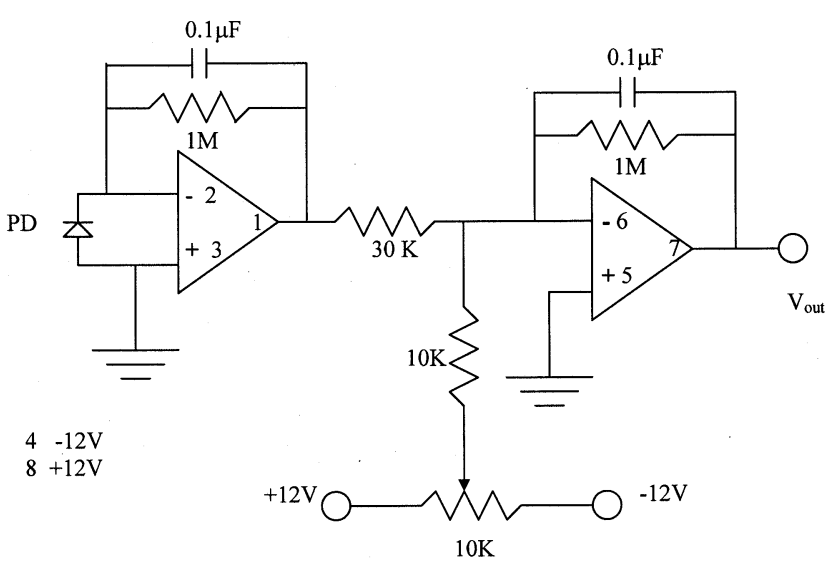

Fig. 4. Absorbance detector signal processing circuit.

$1 \mathrm{mM} \mathrm{NaOH}$ was used as the carrier and delivered at a constant flow rate of $47 \mu \mathrm{L} / \mathrm{min}$ with a peristaltic pump (Dynamax RP-1, Rainin Inc., Emeryville, CA) to the channel inlet. The analyte solution was injected using a 6-port chromatographic valve (VICI Instruments, Houston, TX). Although the actual injection loop in this valve was $20 \mu \mathrm{L}$, time based injection was used to inject a smaller sample volume, estimated to be $<8 \mu \mathrm{L}$. Rather than using a commercial current amplifier, we opted to use what could be easily and inexpensively incorporated on a wafer-scale device. An inexpensive dual JFET operational amplifier (TL082, Texas Instruments) was used to provide both gain and offset to the photodiode output. The electronic circuitry is schematically shown in Fig. 4. The amplifier output was acquired and displayed on a notebook PC using a 12-bitA/D card (PC-CARD-DAS16/12AO, Measurement Computing Corporation, Middleboro, MA) with a data acquisition rate of $1 \mathrm{~Hz}$. Conformity to Beer's law was measured by injecting different concentrations of BTB into the test system and converting the transmittance signal to absorbance (the baseline signal was taken as $I_{0}$ ).

Applicability to fluorescence detection was ascertained by coupling a high current, high intensity blue LED (Luxeon Emitter LXHL-BR01, center wavelength: $455 \mathrm{~nm}$, Lumileds
TABLE II

Light ThroughPUT (PHOTOCURRENT) IN THE LCW Versus THE CONTROL WAFER CHANNELS

\begin{tabular}{|c|c|c|c|}
\hline & LCW $(I, \mathbf{n A})$ & Control (I, nA) & Ratio \\
\hline (a) straight channel (F-F $\left.\mathrm{F}^{\mathrm{b}} 23 \mathrm{~mm}\right)$ & $211(8.2 \%)^{\mathrm{a}}$ & $13.0(11 \%)^{\mathrm{a}}$ & 16 \\
\hline (b) curved channel $1\left(\mathrm{r}_{\mathrm{c}} 6.1 \mathrm{~cm}, \mathrm{~F}-\mathrm{F} 19 \mathrm{~mm}\right)$ & $111(11 \%)^{\mathrm{a}}$ & $0.61(48 \%)^{\mathrm{a}}$ & 182 \\
\hline (c) curved channel $2\left(\mathrm{r}_{\mathrm{c}} 1.9 \mathrm{~cm}\right.$, F-F $\left.19 \mathrm{~mm}\right)$ & $0.93(8.6 \%)^{\mathrm{a}}$ & $0.11(9.1 \%)^{\mathrm{a}}$ & 8.5 \\
\hline (d) curved channel $2\left(\mathrm{r}_{\mathrm{c}} 1.9 \mathrm{~cm}, \mathrm{~F}-\mathrm{F} 10 \mathrm{~mm}\right)$ & $8.8(6.8 \%)^{\mathrm{a}}$ & $1.36(19 \%)^{\mathrm{a}}$ & 6.5 \\
\hline
\end{tabular}

LLC, San Jose, CA) driven at $250 \mathrm{~mA}$ to a 3-mm sapphire ball lens (manufacturer's specification on this LED: typical luminous flux $4 \mathrm{~lm}$ when driven at $350 \mathrm{~mA}$ with a junction temperature of $25^{\circ} \mathrm{C}$ ). The LED was placed in an opaque holder such that light was emitted only through the lens. The LED, with its holder, was placed on a small piece of blue plastic filter (\# 863, Edmund Scientific, Barrington, NJ). This assembly was placed on the wafer at the channel location with an optical aperture created by black electrical tape, located $\sim \mathrm{mm}$ from the light collection fiber optic bundle inserted into the channel. The distal end of the bundle was connected to a miniature photomultiplier tube (PMT, H5784, Hamamatsu Co.) covered with a filter stack. A combination of a yellow plastic filter (\#809, Edmund) and a long-pass glass filter (KV500, Schott Glass Technologies. 50\% cut off at $500 \mathrm{~nm}$ ) was used to limit the wavelength range passed to the PMT. Flow injection was carried out by injecting $\sim 20 \mu \mathrm{L}$ of fluorescein, at specified concentrations, with $1 \mathrm{mM} \mathrm{NaOH}$ carrier fluid flowing at $70 \mu \mathrm{L} / \mathrm{min}$.

\section{RESULTS AND DISCUSSION}

\section{A. Light Throughput}

Compared to the $5-7 \mathrm{~mm}$ path lengths used by Tiggelaar $\mathrm{et} \mathrm{al}$. [3], we tested the light throughput under the following conditions: a) straight channels, $23 \mathrm{~mm}$; b) curved channel $1\left(r_{c}=\right.$ $6.1 \mathrm{~cm}$ ), fiber-to-fiber path length $19.5 \mathrm{~mm}$; c) curved channel 2 $\left(r_{c}=1.9 \mathrm{~cm}\right)$, fiber-to-fiber path length $19.9 \mathrm{~mm}$; and d) curved channel $2\left(r_{c}=1.9 \mathrm{~cm}\right)$, fiber-to-fiber path length $10.4 \mathrm{~mm}$. The light throughput cross section is $0.067 \mathrm{~mm}^{2}$ for the control wafer and $0.062 \mathrm{~mm}^{2}$ for the LCW wafer. The results, that include the relative standard deviation (RSD) of triplicate measurements in each case, are shown in Table II. The LCW effect is apparent in both the straight and the curved channel with $r_{c}=6.1 \mathrm{~cm}$. The results for the highly curved channel with $r_{c}=1.9 \mathrm{~cm}$ are significantly poorer. The commercial LCW tube demonstrated nearly constant throughput for curvatures down to $r_{c}=3.0 \mathrm{~cm}$. Below this curvature, geometric deformations occur in these tubes and tests could not be conducted. It may be noted that with a 19-mm source-detector separation, standard laboratory polyethyelene tubing showed negligible throughput regardless of curvature.

For the transverse illumination studies, we measured the fluorescein emission peak intensity (at $540 \mathrm{~nm}$ ) versus distance between illumination point and tube/channel end for straight chan- 
nels. In all cases, the data fit well an exponential decay pattern according to $I=I_{0} e^{-\alpha L}$ where $I$ and $I_{0}$ are the transmitted and incident light intensities, $\mathrm{L}$ is the lateral distance between the transverse illumination source and the detector and $\alpha$ is the attenuation coefficient. Values of $\alpha$, corrected for the attenuation of the fluorescein solution (measured to be $180 \mathrm{M}^{-1} \mathrm{~cm}^{-1}$ ) were $0.07 \pm 0.01,0.25 \pm 0.01$, and $1.09 \pm 0.01 \mathrm{~cm}^{-1}$ for the commercial tube, the coated channel and the uncoated channel, respectively. While the coated microchannels are not as good light conduits as the extruded tubes, they are substantially superior to the uncoated channels, as found in the longitudinally launched absorption measurements, summarized in Table II (b).

There is a greater light loss in the coated micro-channels compared to an extruded Teflon AF tube because a) the channels are not of cylindrical shape which will lead to the lowest losses; in fact, the etched channels may not have exactly uniform cross-section due to variations in the etching and deposition processing over a long etching period, b) etching deep channels in silicon in this manner results in surface irregularities and all the roughness may not be entirely removed by the coating. While the postbake procedure appears to smoothen the coating, microscopic observations suggest that the surface finish is still not as good as that of extruded tubes. In any case, the light throughput in the coated case is good enough to obtain excellent analytical results as demonstrated in the following sections. It is to be also noted that for the straight channel, even though we have less than half the light throughput cross section and nearly four times the path length, the photocurrent for our straight path LCW cell is still an order of magnitude greater compared to that reported by Tiggelaar et al. [3], both cases using comparable LED sources.

\section{B. FIA Signals and Absorbance Detection Performance}

Fig. 5 shows response of the system to repeated injections of the BTB solution into a flowing carrier of $1 \mathrm{mM} \mathrm{NaOH}$. The results are shown both for the Teflon AF-coated wafer and the control wafer, offset for clarity. Approximately $1 \%$ of the signal that is observed for the LCW is observed with the control (observable only after a large magnification). This suggests that whatever light does pass through the channels probably does so by grazing angle propagation along the walls and has little relationship with the liquid core. For the LCW cell, the reproducibility of the response is good (0.9\% RSD).

Without offset and at the same photodiode amplifier gain, the baseline signal in the LCW case shown in Fig. 5 would lie at $\sim 30 \mathrm{~V}$. The baseline noise that we observe, part of which is clearly attributable to the A/D conversion noise (for the 12-bit $\mathrm{A} / \mathrm{D}$ used in the $\pm 10 \mathrm{~V}$ scale, 1-bit noise is equivalent to $4.9 \mathrm{mV}$ ) is $7.6 \mathrm{mV}$. This translates to a transmittance noise of $0.025 \%$ $\mathrm{T}$ and in terms of absorbance, $1.1 \times 10^{-4}$ absorbance units, respectable for the simple circuit and the miniature cell.

The linearity and adherence to Beer's law was studied over a range of $2-100 \mu \mathrm{M}$ BTB injected. The linearity is excellent over this $\sim 2$ orders of magnitude span, with a linear $r^{2}$ value of 0.9993. The results are shown in Fig. 6.

Fluorescence detection was investigated to ascertain practical limits of fluorescence detection limits that can be attained by presently available inexpensive solid-state sources. One interesting aspect of transverse fluorescence detection in this

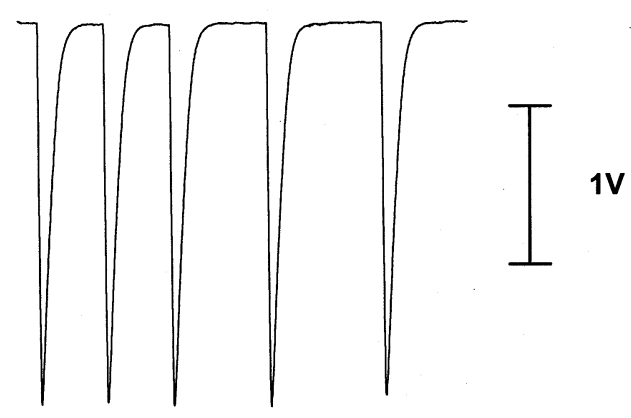

(a)

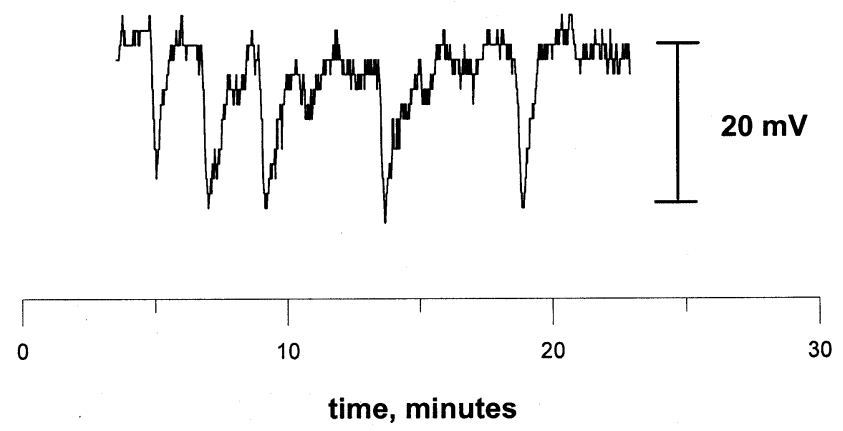

(b)

Fig. 5. Flow injection system output for repeated injections of $70 \mu \mathrm{M}$ Bromthymol Blue ( $\sim \rho \mu \mathrm{L})$ in a $1 \mathrm{mM} \mathrm{NaOH}$ carrier $(47 \mu \mathrm{L} / \mathrm{min})$. (a) Upper trace shows results for Teflon AF-coated channels; (b) the lower trace the same for uncoated channels, $50 \times$ amplified and appropriately offset.

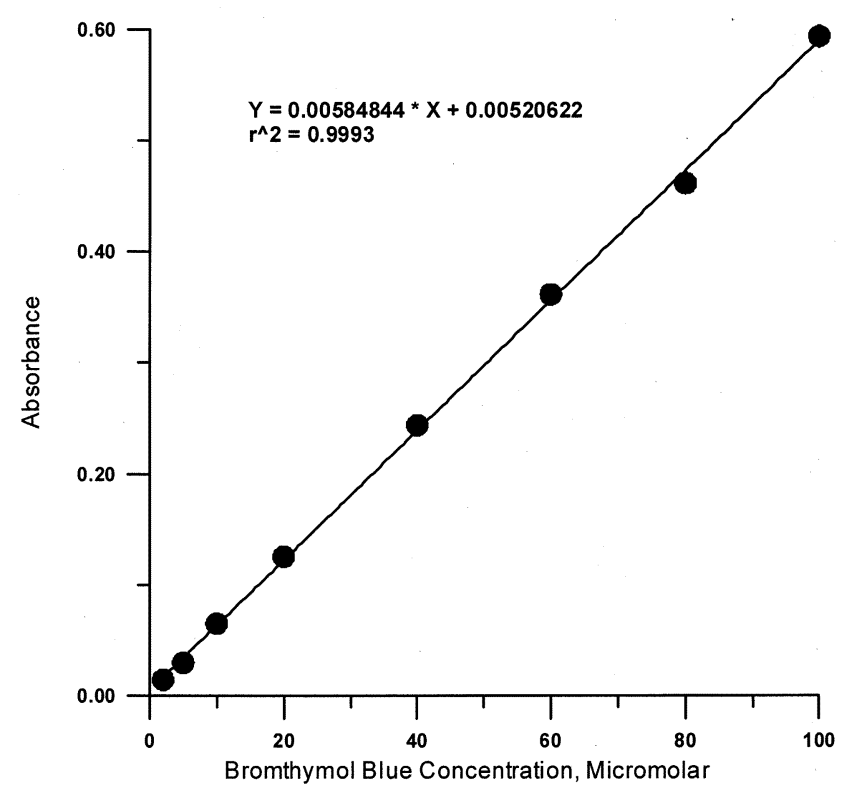

Fig. 6. Beer's law plot for different concentrations of dye injected.

manner with solid state sources is that sources emitting at different wavelengths can be aligned in an array along a channel and the excitation wavelength can be temporally scanned by serially turning on each emitter. For the present purpose of dedicated wavelength fluorescence detection, we chose fluorescein because it is an inexpensive common fluorescent tag that is used widely. The results are shown in Fig. 7 for single digit $\mathrm{nM}$ concentrations of fluorescein injected. We con- 


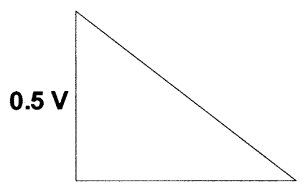

$200 \mathrm{~s}$

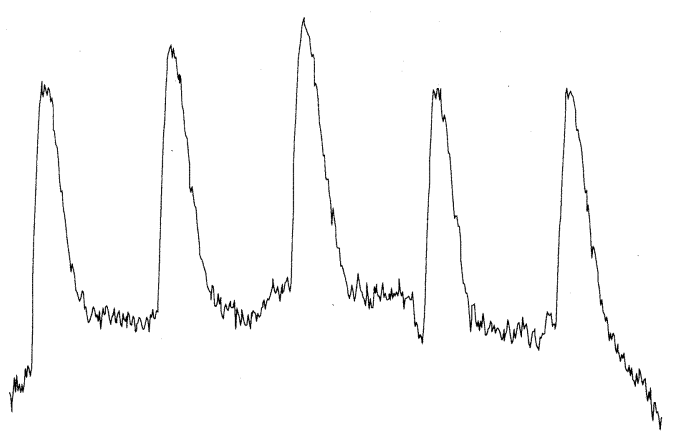

(a)

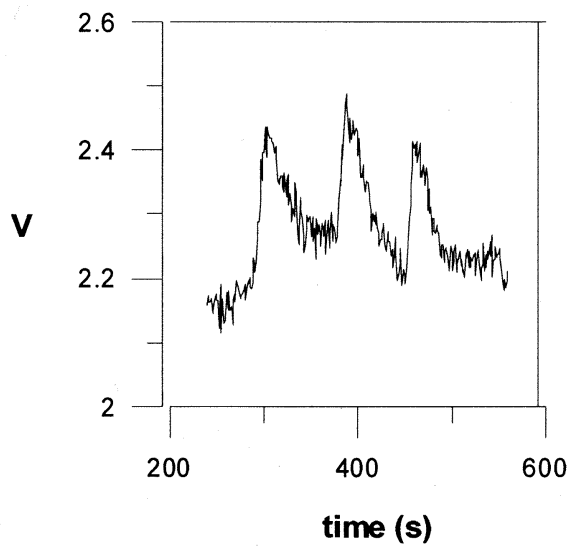

(b)

Fig. 7. Flow injection system output for repeated injections $(\sim 20 \mu \mathrm{L})$ of (a) 9-nM and (b) 3-nM Fluorescein sample in a $1 \mathrm{mM} \mathrm{NaOH}$ carrier $(70 \mu \mathrm{L} / \mathrm{min})$.

servatively estimate that the $S / N=3$ LOD is $\sim 3 \mathrm{nM}$ (inset, Fig. 7). The illuminated volume is about $0.14 \mu \mathrm{L}$; this results in a mass detection limit of 410 attomoles, or $\sim 250$ million molecules. Given the capital cost with which this detection can be performed, we deem it to be excellent.

\section{SUMMARY}

We have developed a process for coating flat glass surfaces and etched microchannels in silicon with low R. I. Teflon AF, and successfully bonded the respective wafers to form sealed microchannels. When filled with aqueous solutions, the channels demonstrated significantly enhanced optical waveguide properties when compared to control channels identically fabricated but left uncoated. The microfabricated LCW can be used for high sensitivity measurements. Future work will refine the fabrication process to yield smoother channels for complete analysis devices.

\section{REFERENCES}

[1] G. Kipshidze, V. Kuryatkov, B. Borisov, M. Holtz, S. Nikishin, and H. Temkin, "AlGaInN-based ultraviolet light emitting diodes grown on Si(111)," Appl. Phys. Lett., vol. 80, pp. 3682-3684, 2002.
[2] E. Verpoorte, A. Manz, H. Lüdi, A. E. Bruno, F. Maestre, B. Krattiger, H. M. Widmer, B. H. van der Shoot, and N. F. de Rooij, "A silicon flow cell for optical-detection in miniaturized total chemical-analysis systems," Sens. Actuators B, vol. 6, pp. 66-70, 1992.

[3] R. M. Tiggelaar, T. T. Veenstra, R. G. P. Sanders, J. G. E. Gardeniers, M. C. Elwenspoek, and A. Van den Berg, "A light detection cell to be used in a micro analysis system for ammonia,” Talanta, vol. 56, pp. 331-339, 2002.

[4] S. J. Ding, P. F. Wang, D. W. Zhang, J. T. Wang, and W. W. Lee, "A novel structural amorphous fluoropolymer film with an ultra-low dielectric constant," Mater. Lett., vol. 49, pp. 154-159, June 2001.

[5] J. H. Lowry, J. S. Mendelowitz, and N. S. Subramanian, "Optical characteristics of Teflon AF fluoroplastic materials,” Opt. Eng., vol. 31, pp. 1982-1985, 1992.

[6] Teflon AF Product Information, Du Pont.

[7] P. K. Dasgupta, Z. Genfa, J. Li, C. B. Boring, S. Jambunathan, and R. Al-Horr, "Luminescence detection with a liquid core waveguide," Anal. Chem., vol. 71, pp. 1400-1407, 1999.

[8] J. Li, P. K. Dasgupta, and Z. Genfa, "Transversely llluminated liquid core waveguide based fluorescence detection. Fluorometric flow injection determination of aqueous ammonium/ammonia," Talanta, vol. 50, pp. 617-623, 1999.

[9] R. H. Byrne, W. Yao, E. Kaltenbacher, and R. D. Waterbury, "Construction of a compact spectrofluorometer/spectrophotometer system using a flexible liquid core waveguide," Talanta, vol. 50, pp. 1307-1312, 2000.

[10] J. Li and P. K. Dasgupta, "Measurement of atmospheric hydrogen peroxide and hydroxymethyl hydroperoxide with a diffusion scrubber and light emitting diode -liquid core waveguide based fluorometry," Anal. Chem., vol. 72, pp. 5338-5347, 2000.

[11] J. Li, P. K. Dasgupta, Z. Genfa, and M. A. Hutterli, "Measurement of atmospheric formaldehyde with a diffusion scrubber and light emitting diode-liquid core waveguide based fluorometry," Field Anal. Chem. Technol., vol. 5, pp. 2-11, 2001.

[12] S.-L. Wang, X.-J. Huang, Z.-L. Fang, and P. K. Dasgupta, “A miniaturized liquid core waveguide-capillary electrophoresis system with flow injection sample introduction and fluorometric detection using lightemitting diodes," Anal. Chem., vol. 73, pp. 4545-4549, 2001.

[13] J. Li and P. K. Dasgupta, "Chemiluminescence detection with a liquid-core waveguide. determination of ammonium with electrogenerated hypochlorite based on the luminol-hypochlorite reaction," Anal. Chim. Acta, vol. 398, pp. 33-39, 1999.

[14] — - "Measurement of gaseous hydrogen peroxide with a liquid core waveguide chemiluminescence detector," Anal. Chim. Acta, vol. 442, pp. 63-70, 2001.

[15] R. Altkorn, I. Koev, R. P. Van Duyne, and M. Litorja, "Low-loss liquid-core optical fiber for low-refractive-index liquids: Fabrication, characterization, and application in raman spectroscopy," Appl. Opt., vol. 36, pp. 8992-8998, 1997.

[16] L. Song, S. Liu, V. Zhelyaskov, and M. A. El-Sayed, "Application of liquid waveguide to raman spectroscopy in aqueous solution," Appl. Spectrosc., vol. 52, pp. 1364-1367, 1998.

[17] M. Holtz, P. K. Dasgupta, and G. Zhang, "Small-volume raman spectroscopy with a liquid core waveguide," Anal. Chem., vol. 71, pp. 2934-2938, 1999.

[18] R. Altkorn, I. Koev, and M. Pelletier, "Raman performance characteristics of Teflon AF 2400 liquid-core optical-fiber sample cells," Appl. Spectrosc., vol. 53, pp. 1169-1176, 1999.

[19] B. Marquardt, P. Vahey, R. Synovec, and L. Burgess, "A raman waveguide detector for liquid chromatography," Anal. Chem., vol. 71, pp. 4808-4814, 1999.

[20] R. Altkorn, M. D. Malinsky, R. P. Van Duyne, and I. Koev, "Intensity considerations in liquid core optical fiber raman spectroscopy," Appl. Spectrosc., vol. 55, pp. 373-381, Apr. 2001.

[21] P. Dress and H. Franke, "A cylindrical liquid-core waveguide," Appl. Phys. B: Laser Opt., vol. 63, pp. 12-19, 1996.

[22] - "An optical fiber with a $\mathrm{H}_{2} \mathrm{O}$ core," Proc. SPIE, vol. 2686, pp. 157-163, 1996.

[23] R. D. Waterbury, W. Yao, and R. H. Byrne, "Long pathlength absorbance spectroscopy: Trace analysis of Fe(ii) using a $4.5 \mathrm{~m}$ liquid core waveguide," Anal. Chim. Acta, vol. 357, pp. 99-102, 1997.

[24] R. Altkorn, I. Koev, and A. Gottlieb, "Waveguide capillary cell for low-refractive-index liquids,” Appl. Spectrosc., vol. 51, pp. 1554-1558, 1997.

[25] P. DeLand, Raising the Sensitivity Benchmark in Diode Array Detection With Optical Improvements: American Laboratory, 1997, pp. 19-24.

[26] P. K. Dasgupta, Z. Genfa, S. K. Poruthoor, S. Caldwell, S. Dong, and S.-Y. Liu, "High sensitivity gas sensors based on gas permeable liquid core waveguides and long-path absorbance detection," Anal. Chem., vol. 70, pp. 4661-4669, 1998. 
[27] P. Dress, M. Belz, K. Klein, K. Grattan, and H. Franke, "Water-core waveguide for pollution measurements in the deep ultraviolet," Appl. Opt., vol. 37, pp. 4991-4997, 1998.

[28] M. Belz, P. Dress, K. Klein, W. Boyle, H. Franke, and K. Grattan, "Liquid core waveguide with fiber optic coupling for remote pollution monitoring in the deep ultraviolet," Water Sci. Technol., vol. 37, pp. 279-284, 1998

[29] W. Yao, R. H. Byrne, and R. D. Waterbury, "Determination of nanomolar concentrations of nitrite and nitrate in natural waters using long path length absorbance spectroscopy," Environ. Sci. Technol., vol. 32, pp. 2646-2649, 1998.

[30] C. Gooijer, G. Hoornweg, T. de Beer, A. Bader, D. van Iperen, and U. Brinkman, "Detector cell based on plastic liquid-core waveguides suitable for aqueous solutions: One-to-two decades improved detection limits in conventional-size column liquid chromatography with absorption detection," J. Chromatograph. A, vol. 824, no. 1-5, 1998

[31] W. Yao and R. H. Byrne, "Determination of trace chromium(VI) and molybdenum(VI) in natural and bottled mineral waters using long pathlength absorbance spectroscopy (LPAS)," Talanta, vol. 48, pp. 277-282, 1999.

[32] S. Jambunathan and P. K. Dasgupta, "Determination of hexavalent chromium in leather extracts by the diphenylcarbazide (IUC-18) procedure: Pitfalls and refinements," J. Soc. Leather Technol. Chem., vol. 84, pp. 63-73, 2000

[33] M. R. Milani and P. K. Dasgupta, "Measurement of nitrogen dioxide and nitrous acid using gas-permeable liquid core waveguides," Anal. Chim. Acta, vol. 431, pp. 169-180, 2001

[34] K. Hong and L. W. Burgess, "Liquid-core waveguides for chemical sensing," Proc. SPIE, vol. 2293, p. 71, 1994.

[35] S. J. Mackenzie and J. P. Dakin, "Internally Teflon-AF coated capillary cell for optical fiber remote spectroscopy," in Proc. Conf. Lasers and Electro-Optics Europe, 1996, p. 206.

[36] A. van den Berg, W. Olthuis, and P. Bergveld, Eds., Micro Total Analysis Systems 2000. Dordrecht, The Netherlands: Kluwer, 2000.

[37] [Online]. Available: http://www.transene.com/sio2.html\#buffer

[38] K. Endo, K. Shinoda, and T. Tatsumi, "Plasma deposition of low-dielectric-constant fluorinated amorphous carbon," J. Appl. Phys., vol. 86, p. 2739,1999

[39] S. Robles, L. Vasquez, M. Eizenberg, and F. Moghadam, "Characterization of high density plasma deposited a-carbon and a-fluorinated carbon films for ultra low dielectricapplications," in Proc. 3rd Int. Dielectrics for ULSI Multilevel Interconnection Conf., 1997, pp. 26-33.

[40] S. Gangopadhyay, X. Wang, H. Harris, G. Celebi, K. Bouldin, D. Lamp, and H. Temkin, "Optical, electrical and plasma etch properties of thermally stable low-k fluorinated amorphous carbon films," in Proc. 5th Int. Conf. Dielectrics for ULSI Multilevel Interconnect, 1999, pp. 25-30.

[41] X. Wang, H. R. Harris, K. Bouldin, H. Temkin, and S. Gangopadhyay, "Structural properties of fluorinated amorphous carbon films," J. Appl. Phys., vol. 87, pp. 621-623, 2000.

[42] N. Biswas, R. Harris, X. Wang, H. Temkin, and S. Gangopadhyay, "Electrical properties of fluorinated amorphous carbon films," J. Appl. Phys., vol. 89, pp. 4417-4421, 2001.

[43] [Online]. Available: http://www.cytonix.com/fluoroSyl.html.

[44] P. Dress, M. Belz, K. Klein, K. Grattan, and H. Franke, "Physical analysis of teflon coated capillary waveguides," Sens. Actuators B, vol. 51, pp. 278-284, 1998

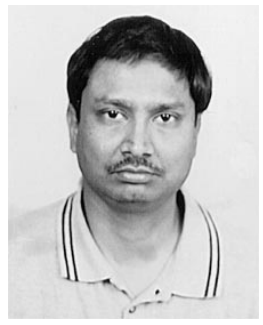

Arindom Datta received the Ph.D. degree in materials science from the Indian Institute of Technology, Kharagpur, in 2001.

His broad area of research is growth and characterization of electronic materials and processing. $\mathrm{He}$ worked on diffusion barriers for copper metallization at the School of Materials Science and Engineering, Seoul National University, Seoul, Korea, from February 2000 to August 2001 as a Postdoctoral Fellow. Since August 2001, he has been a Research Associate in the Nano Tech Center, Texas Tech University (TTU), Lubbock. His principal research area at TTU is microelectromechanical systems (MEMS) with emphasis on liquid core waveguide, plasma processing, anodic bonding, and nanochannel. He has published twelve papers in refereed journals and conference proceedings and has eight conference presentations.

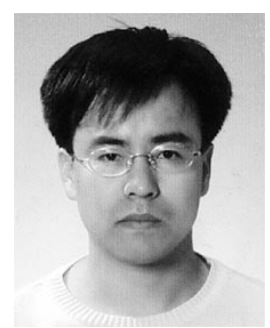

In-Yong Eom was born in Wonju, Korea, on January, 1971. He received the B.S. degree and the M.S. degree in chemistry from Kangwon National University, Korea, in 1995 and 1997, respectively. He is currently pursuing the Ph.D. degree, under the guidance of Prof. P. K. Dasgupta, at Texas Tech University, Lubbock.

His research focus is on the use of solid state light sources in analytical chemistry.

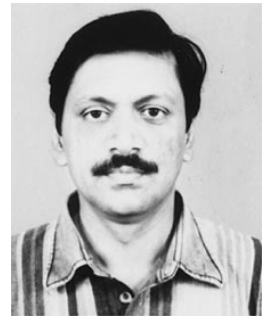

Achintya Dhar was born in Naogaon, India, in 1961. $\mathrm{He}$ received the M.Sc. and Ph.D. degrees in physics from Calcutta University, Calcutta, India in, 1984 and the Ph.D. degree in physics from Jadavpur University, India, in 1991. His doctoral research involved compound semiconductor materials for solar applications.

He joined the Indian Institute of Technology (IIT), New Delhi, as Project Officer and worked on phasechange optical materials. He joined IIT, Kharagur, in 1994 as Scientific Officer. He has worked on high temperature superconducting oxide materials, giant magneto-resistive oxides, high-k dielectric materials, and microelectromechanical systems devices. His current interests are focused on the growth and characterization of nano-structured materials for sensor applications.

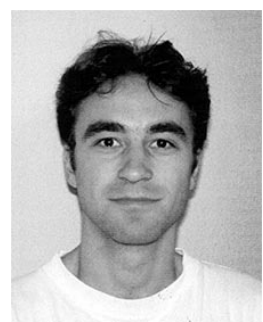

Petr Kuban received the B.Sc.degree in chemistry and the M.Sc. degree in analytical chemistry from Masaryk University, Brno, Czech Republic, in 1996, and the Ph.D. degrees in analytical chemistry from Stockholm University, Sweden, and in agricultural chemistry from Mendel University, Brno, both in 2000.

Currently, he is a Senior Research Fellow in the Department of Chemistry and Biochemistry, Texas Tech University, Lubbock, in Prof. P. K. Dasgupta's laboratory. His primary research interest is in flow injection analysis, microanalytical systems, miniaturization, and capillary electrophoresis.

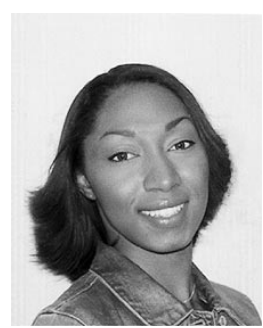

Rosalynn Manor is currently a graduate student in electrical engineering at Texas Tech University (TTU), Lubbock.

She is a Research Assistant in the field of microfluidic system fabrication using semiconductor-processing techniques at TTU. In 2000, she was an intern at International SEMATECH conducting optimization experiments for 193-nm lithography processes for the 130-nm manufacturing node. Her research interests are in MEMS device fabrication and analysis for bioengineering applications. She is currently researching techniques for the fabrication of microfluidic channels with optical waveguide properties.

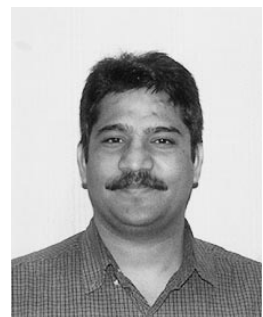

Iftikhar Ahmad received the M.Sc. degree in physics from the Government College Lahore, Pakistan, in 1992 and the the M.S. degree in physics from Texas Tech University (TTU), Lubbock, in 2002. He is currently pursuing the Ph.D. degree at TTU.

He had an industrial internship at Applied Materials, Inc., where he was concerned with optical modeling of RTP systems. His research interests include optical characterization of III-V nitrides and optical characterization of microfluidic channels. 


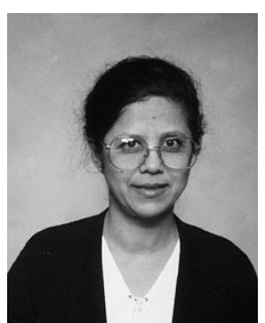

Shubhra Gangopadhyay received the Ph.D. degree in physics from the Indian Institute of Technology, Kharagpur, in 1982.

From 1983 to 1985 , she was a Visiting Scientist at Universitat Kaiserslautern, Germany, working on semiconductor physics. Since 1985, she has been with the Department of Physics, Texas Tech University, Lubbock, working in the areas of material science, semiconductor device physics, microelectronics, and microsensors. She joined the University of Missouri, Columbia, in the Fall of 2003 as a LaPierre Chair Professor, Department of Electrical Engineering.

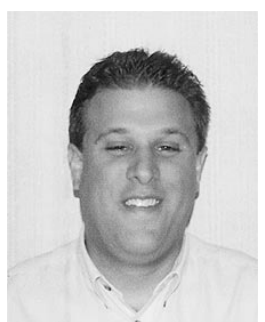

Tim Dallas received the B.A. degree in physics from the University of Chicago, Chicago, IL, in 1991. He received the M.S. and Ph.D. degrees in physics from Texas Tech University (TTU), Lubbock, in 1993 and 1996, respectively, with research focused on using optical spectroscopy to study disordered carbon materials.

Following a year in the semiconductor equipment industry working on advanced lithography systems as an Applications and Technology Engineer, he was a Postdoctoral Research Fellow at the University of Texas, Dallas, in the Department of Chemical Engineering. Since 1999, he has been an Assistant Professor of Electrical and Computer Engineering at TTU, where he is also the Associate Director of the Nano Tech Center. His research interests include microfabrication techniques, microanalysis systems, novel graduate education, and optical simulation of microoptoelectromechanical systems.

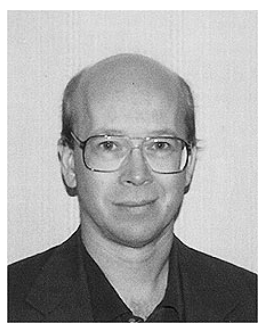

Mark Holtz received the B.S. degree in physics from Bradley University, Peoria, IL, and the Ph.D. in physics from Virginia Polytechnic Institute and State University, Blacksburg, in 1980 and in 1987, respectively.

He was a Fellow at the Max Planck Institute, Stuttgart, Germany, working in high-pressure physics. From 1989 through 1991, he was a Research Associate at Michigan State University, East Lansing. Since 1991, he has been with the Department of Physics, Texas Tech University, Lubbock, working in semiconductors, optical spectroscopy, and recently in metallic thin films and microfluidics.

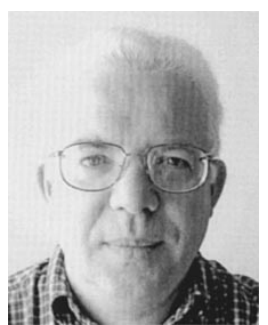

Henryk Temkin (F'91) received the B.S. degree in physics from the Universite Libre de Bruxelles, Brussels, Belgium, 1969, the M.A. degree in physics from the Belfer Graduate School of Science, Yeshiva University, New York, in 1971, and the Ph.D. degree from the Stevens Institute of Technology, Hoboken, $\mathrm{NJ}$, in 1975.

He has been a Paul W. Horn Professor and Maddox Chair in the Electrical and Computer Engineering Department, Texas Tech University, Lubbock, since 1996. He was a Distinguished Member of the Technical Staff in the Physics Division of Bell Laboratories, Murray Hill, NJ, between 1977 and 1992. His professional interests include epitaxial growth of semiconductors, optoelectronic devices, and passive integrated optics devices. $\mathrm{He}$ is the author or coauthor of over 350 publications.

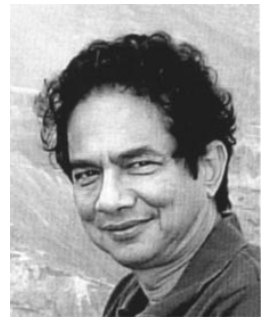

Purnendu K. Dasgupta received the Ph.D. degree in analytical chemistry (with a minor in electrical engineering) from Louisiana State University, Baton Rouge, in 1977.

He is a Paul W. Horn Professor of chemistry and biochemistry at Texas Tech University, Lubbock, where he has been since 1981. His research interests include fluid flow in thin films, thin-film specific chemical sensors, atmospheric chemistry and sensing, automated intelligent analyzers, microscale analytical systems, automated process analysis, and novel approaches to ionic analysis. 